\title{
Rates of, and the factors affecting, cycle helmet use among secondary schoolchildren in East Sussex and Kent
}

\author{
P Colin Cryer, Jeremy Cole, Leslie L Davidson, Mohammed Rahman, Vivian Ching, \\ Janet B Goodall
}

South East Institute of Public Health, United Medical and Dental Schools of Guy's and St Thomas' Hospitals, London, UK

P C Cryer

East Sussex Brighton and Hove Health Authority

J Cole

Lambeth, Southwark and Lewisham Health Authority, and King's College School of Medicine and Dentistry, London L L Davidson

Department of Computing and Statistics, Brighton University

M Rahman

Department of Operational Research, London School of Economics and Political Science V Ching

Area Road Safety, Kent Highways

J B Goodall

Correspondence to: Dr Colin Cryer, South Eas Institute of Public Health, David Salomons' Estate, Broomhill Road, Tunbridge Wells, Kent, TN3 0XT, UK.

\begin{abstract}
Objectives-To assess the level of cycle helmet wearing among young people in two counties in the South East of England in 1994, and to identify the factors associated with helmet wearing.

Design-Cross sectional survey in a convenience sample.

Setting-Secondary schools in East Sussex and Kent.

Subjects-Students in year 7 (aged 10-12 years) and year 11 (aged 14-16 years).

Main outcome measures-Self reported "always wears a helmet".

Results-Among those who ride a bicycle, $32 \%$ of boys and $29 \%$ of girls aged $10-12$ years, and $14 \%$ of boys and $10 \%$ of girls aged 14-16, reported that they always wear helmets. The variables that were most consistently associated with helmet wearing (that is significantly associated with helmet wearing in at least five of the six age, sex, and county subgroups) were: "parental encouragement to wear a helmet", "closest friend wears a helmet", "belief that laws that make children wear helmets are good", and "sometimes rides off-road".

Conclusions-The self reported rates of always wearing a cycle helmet in East Sussex and Kent are consistent with overseas findings for populations who had not been exposed to intensive helmet promotion. The evidence suggests that parental encouragement has a favourable effect on rates of cycle helmet use among secondary schoolchildren, which is separate from and additional to peer influences. When designing a helmet promotion programme, therefore, it will have added impact if both parents and children are addressed.

(Injury Prevention 1998;4:106-110)
\end{abstract}

Keywords: bicycles; helmets; wearing rates

Bicycles are an attractive means of transport. They are inexpensive and relatively easy to maintain. By substituting bicycle for car use, cycling can confer a positive benefit to the environment, and simultaneously increase physical fitness. However, while cycling offers numerous benefits, it also carries risks. Over the last 30 years, the risk of an adult being killed in a cycling accident in Britain has risen per kilometre cycled and is substantially higher than in many other European countries. ${ }^{1}$ Two thirds of deaths resulting from cycling are the result of head injuries ${ }^{2}$ and between half and three quarters of injured cyclists using hospital services had a head injury. ${ }^{3-5}$

The weight of evidence suggests that helmets are effective in preventing or reducing the severity of some head injuries. ${ }^{67}$ However, Vulcan and Lane argue that the $85 \%$ reduction in the risk of head injury, and the $88 \%$ reduction in the risk of brain injury resulting from cycle helmet wearing, estimated by Thompson et al, ${ }^{6}$ should be regarded as upper limits. ${ }^{8}$

Among children who have been subject to little or no bicycle helmet promotion, the rate of helmet wearing tends to be below $15 \% .^{8-13}$ Exposure to cycle helmet promotion can increase the rate substantially, ${ }^{9}{ }^{10} 12$ even higher rates can be achieved where intensive and multifaceted helmet promotion methods are used, ${ }^{81415}$ and higher rates still (up to $90 \%$ ) with the enactment of legislation to make helmet wearing compulsory on top of this intensive helmet promotion. ${ }^{15} 16$

The current study aimed to assess the level of cycle helmet wearing among young people in two counties in the South East of England in 1994, and to identify the factors associated with helmet wearing. The identification of factors, in the local population, that appear to influence helmet wearing will guide future health promotion planning and the prevalence of helmet wearing will provide a baseline against which the success of future health promotion activities can be judged.

\section{Methods}

Self completion questionnaires, adapted for the UK from an instrument used in a similar survey in the USA, ${ }^{17}$ were delivered to $23 \mathrm{sec}-$ ondary schools in the counties of Kent and East Sussex in December 1994. These were completed anonymously during supervised class time by the students in year 7 (aged 10-12 years) and year 11 (aged 14-16 years). Data were collected on the variables listed in table 1.

All East Sussex secondary schools were invited, and $13 / 35$ agreed to take part in this survey. The Kent schools (10/128) were chosen systematically to include both grammar and other secondary schools. All pupils present on the day of the survey in year 7 (median age 11) and year 11 (median age 15) took part.

All students to whom the questionnaires were presented completed them; $68 \%$ of these were from East Sussex schools and 32\% from 
Table 1 Variables derived from the questionnaire data

\begin{tabular}{lc}
\hline - Age & - Helmet promotion from: \\
- Sex & School nurse \\
- County & Teacher \\
- School & Youth worker \\
- Rides a bicycle & Doctor \\
- Helmet ownership & Police \\
- Helmet use & Road safety advisor \\
- Parental encouragement & - Attended proficiency course \\
- Parental helmet use & Beliefs (social consequences): \\
- Friends wear a helmet & Laughing/teasing \\
- Closest friend wears a helmet & Less fun to ride \\
- Time spent riding & Poor appearance \\
- Riding: & Belief (physical consequences): \\
For fun & Can save lives \\
To get to school & Protects against injury \\
To do a paper round & Beliefs (other): \\
For a sporting activity & Helmets cost too much \\
To your friend's home & Helmets not comfortable \\
For other reasons & Helmet laws are good \\
- Riding: & Attitude: \\
On roads & Rather not ride if have to wear a helmet \\
Off-road & \\
To and from school & \\
\hline
\end{tabular}

Kent. A total of 4087 completed questionnaires were used in the estimation of rates of self reported bicycle riding. Only students who reported that they rode a bicycle and responded to the question about their own cycle helmet wearing were included in the estimates of rates of helmet wearing and the investigation of associations with helmet wearing $(n=3082$; $75 \%$ of all respondents). Similar to Dannenberg et $a l,{ }^{17}$ the measure used for investigating associations with helmet wearing was whether the respondent reported that they always wore a helmet (as opposed to sometimes or never wearing one).

The literature on helmet use has shown that there are significant age differences in helmet wearing rates and there may be significant sex differences, although for sex the evidence is not consistent. Furthermore, there were differences between the two counties in the method of selection and the types of schools selected, as well as in the local government organisations responsible for road safety and hence road safety programmes in the two counties. As a result, there was concern that the results for the two counties, or for age and sex subgroups, would not be equivalent. The analytical strategy was, therefore, to investigate the associations for each age, sex, and county subgroup separately.

Bivariate associations between each of the variables and helmet use were initially investigated. The subgroups considered in the bivariate analysis were all combinations of age, sex and county, as seen from table 2. Then the independent associations of all the variables, shown in table 1 , with helmet wearing were investigated using multiple linear logistic regression analysis, ${ }^{18}$ for each of the age, sex, and county subgroups. Stepwise backward elimination was used, with variables eliminated from the model if they had a $\mathrm{p}$ value greater than 0.1. A number of respondents did not answer all of the survey questions. In order to minimise the effect of the missing values in the logistic regression analysis, the missing values for each of the following variables were treated as a separate category and included in the analysis: riding for fun (18\%), to get to school $(46 \%)$, to do a paper round $(47 \%)$, for a sporting activity $(44 \%)$, to your friend's home $(36 \%)$, riding for other reasons $(50 \%)$, parental encouragement $(11 \%)$, parental helmet use $(2 \%)$, friends wear a helmet $(19 \%)$, closest friend wears a helmet (13\%), and attended a cycling proficiency course $(3 \%)$. The figures in brackets indicate the proportions of missing values for each of these variables among cycle riders.

Table 2 Percentage reporting that they always wear a helmet by selected factors associated with helmet wearing

\begin{tabular}{|c|c|c|c|c|c|c|c|c|}
\hline & \multicolumn{4}{|c|}{ Year 7 (aged 10-12) } & \multicolumn{4}{|c|}{ Year 11 (aged 14-16) } \\
\hline & \multicolumn{2}{|c|}{ East Sussex } & \multicolumn{2}{|l|}{ Kent } & \multicolumn{2}{|c|}{ East Sussex } & \multicolumn{2}{|l|}{ Kent } \\
\hline & $\begin{array}{l}\text { Boys } \\
(\%)^{*}\end{array}$ & $\begin{array}{l}\text { Girls } \\
(\%)\end{array}$ & $\begin{array}{l}\text { Boys } \\
(\%)\end{array}$ & $\begin{array}{l}\text { Girls } \\
(\%)\end{array}$ & $\begin{array}{l}\text { Boys } \\
(\%)\end{array}$ & $\begin{array}{l}\text { Girls } \\
(\%)\end{array}$ & $\begin{array}{l}\text { Boys } \\
(\%)\end{array}$ & $\begin{array}{l}\text { Girls } \\
(\%)\end{array}$ \\
\hline \multicolumn{9}{|c|}{ Parental encouragement to wear a helmet } \\
\hline Yes & 47 & 51 & 55 & 46 & 30 & 26 & 26 & 31 \\
\hline No & 8 & 4 & 3 & 10 & 3 & 3 & 3 & 0 \\
\hline Odds ratio $†$ & 10.2 & 25.0 & 39.5 & 7.7 & 13.9 & 11.4 & 11.4 & $\ddagger$ \\
\hline \multicolumn{9}{|c|}{ Closest friend wears a helmet } \\
\hline Yes & 50 & 49 & 62 & 52 & 52 & 26 & 45 & 35 \\
\hline No & 16 & 16 & 18 & 12 & 4 & 6 & 3 & 4 \\
\hline Odds ratio $†$ & 5.2 & 5.0 & 7.4 & 7.9 & 26.0 & 5.5 & 26.4 & 12.9 \\
\hline \multicolumn{9}{|c|}{ Sometimes rides off-road } \\
\hline Yes & 33 & 37 & 44 & 32 & 17 & 14 & 14 & 14 \\
\hline No & 20 & 16 & 39 & 16 & 25 & 13 & 0 & 13 \\
\hline Odds ratio $\dagger$ & 2.0 & 3.1 & 1.2 & 2.5 & 0.6 & 1.1 & $\ddagger$ & 1.1 \\
\hline \multicolumn{9}{|c|}{ Rather not ride a bicycle if had to wear a helmet } \\
\hline Agree & 7 & 5 & 12 & 7 & 6 & 1 & 2 & 2 \\
\hline Disagree & 42 & 42 & 52 & 34 & 27 & 20 & 21 & 18 \\
\hline Odds ratio $\$$ & 9.6 & 13.7 & 7.9 & 6.8 & 5.8 & 25.0 & 13.0 & 10.8 \\
\hline \multicolumn{9}{|c|}{ Wearing a helmet is uncomfortable } \\
\hline Agree & 18 & 22 & 27 & 16 & 11 & 6 & 4 & 12 \\
\hline Disagree & 59 & 50 & 58 & 49 & 36 & 45 & 43 & 21 \\
\hline Odds ratio $\$$ & 6.5 & 3.5 & 3.7 & 5.1 & 4.5 & 12.8 & 18.2 & 1.9 \\
\hline \multicolumn{9}{|c|}{ Laws that make children wear bicycle safety helmets are good } \\
\hline Agree & 43 & 40 & 49 & 33 & 26 & 14 & 20 & 13 \\
\hline Disagree & 6 & 6 & 17 & 4 & 4 & 0 & 0 & 0 \\
\hline Odds ratio & 11.8 & 10.4 & 4.7 & 11.8 & 8.4 & $\ddagger$ & $\ddagger$ & $\ddagger$ \\
\hline
\end{tabular}


Table 3 Children's self reported bicycle riding, helmet ownership, and wearing rates (denominators for the rates are shown in parentheses)

\begin{tabular}{lll}
\hline & Age 11 & Age 15 \\
\hline Per cent (number) ride a bicycle & $86(2553)$ & $60(1534)$ \\
Male & $89(1265)$ & $76(716)$ \\
Female & $83(1288)$ & $47(818)$ \\
Per cent (number) own a helmet & $69(2187)$ & $38(925)$ \\
Male & $72(1119)$ & $45(542)$ \\
Female & $65(1068)$ & $29(383)$ \\
Per cent wear a helmet (overall) & & \\
Always & 30 & 12 \\
Sometimes & 38 & 22 \\
Never & 31 & 66 \\
& $(2174)$ & $(908)$ \\
Per cent wear a helmet, male & & \\
Always & 32 & 14 \\
$\quad$ Sometimes & 39 & 27 \\
Never & 29 & 59 \\
& $(1110)$ & $(531)$ \\
Per cent wear a helmet, female & & \\
Always & 29 & 10 \\
$\quad$ Sometimes & 37 & 15 \\
Never & 34 & 75 \\
& $(1064)$ & $(377)$ \\
\hline
\end{tabular}

Table 4 Adjusted summary odds ratios for variables associated with helmet wearing in the logistic regression models

\begin{tabular}{|c|c|c|}
\hline Factor & $\begin{array}{l}\text { Odds } \\
\text { ratio }\end{array}$ & $\begin{array}{l}95 \% \\
\text { Confidence } \\
\text { interval }\end{array}$ \\
\hline Parental encouragement & 6.77 & 4.09 to 11.14 \\
\hline Closest friend wears a helmet: age $11^{\star}$ & 2.80 & 2.00 to 3.92 \\
\hline Closest friend wears a helmet: age $15^{\star}$ & 17.17 & 6.86 to 42.73 \\
\hline Sometimes rides off-road & 5.69 & 3.77 to 8.62 \\
\hline
\end{tabular}

In the analysis, children were included in a given age group if they were in a particular year at secondary school at the time of the data collection (year 7 and 11). Children in these years had a range of ages: ages 10-12 for year 7, and ages 14-16 for year 11 . For reporting purposes, the average age for each of the two year groups is stated: 11 and 15 respectively.

In the logistic regression analysis for 11 year old children, the subgroups were: boys in East Sussex, girls in East Sussex, boys in Kent, girls in Kent. For the 15 year old children, the subgroups for the logistic regression analysis were boys combined across county, and girls combined across county. For each variable that showed a consistent, independent association with helmet wearing, a summary odds ratio estimate was produced where a $\chi^{2}$ test for heterogeneity ${ }^{19}$ was not significant. A nonsignificant heterogeneity $\chi^{2}$ test indicated that the odds ratio estimates for each subgroup were not significantly different from one another and so could be combined.

\section{Results}

The percentages of children reporting bicycle riding, helmet ownership and helmet use are shown in table 3 . The level of helmet wearing was substantially less for 15 year old students compared with 11 year old children. Rates were similar for boys and girls at age 11 , but were less for girls than for boys at age 15. Table 2 shows the percentages of students reporting that they always wear a helmet, for each of the main levels of those variables found to be associated with reported helmet use.

Logistic regression analysis, which included all the variables shown in table 1 , showed that only a small number of the variables were consistently associated with self reported helmet use. Among the child specific attitudinal variables, agreement with the statement that "laws that make children wear a helmet are good" were significantly associated at the 5\% level of significance with self reported helmet use for five out of the six age, sex, and county subgroups. Furthermore, agreement with the statements that "helmet wearing is uncomfortable" and "I would rather not ride a bicycle if I had to wear a helmet" were significantly associated with a smaller proportion reporting they always wear a helmet for three out of the four 11 year old groups, but was not significantly associated with reduced helmet wearing for 15 year old boys and girls.

Among the other variables, the ones that were consistently associated with self reported helmet use were: sometimes rides off-road; parental encouragement to wear a helmet; and closest friend wears a helmet.

For each of these variables, there were statistically significant associations, at the 5\% level of significance, with self reported helmet wearing for all the age, sex, and county subgroups considered, with the exception of 15 year old boys for the variable "sometimes rides offroad". Odds ratio estimates, combined across the subgroups, for each of these variables are shown in table 4 .

For the remaining variables considered in the analysis, significant associations with self reported helmet wearing were not found at all or were only found for one of the six subgroups.

\section{Discussion}

The findings that $32 \%$ of boys and $29 \%$ of girls aged $10-12$ years, and $14 \%$ of boys and $10 \%$ of girls aged 14-16 years, reported that they always wear helmets are similar to the helmet wearing rates found in North America in the early 1990s. ${ }^{20-23}$ These North American study populations include a mixture of those who had been exposed to intensive helmet wearing promotion, those who had been exposed to little or no promotion, and all shades between. The rates reported in our study are much lower than those found in Australia and parts of the USA in the early to mid-1990s, many parts of which had been exposed to extensive helmet promotion, and some of which had laws requiring mandatory helmet wearing. ${ }^{14-1624-26}$ In East Sussex and Kent, a multiagency cycle helmet campaign had occurred earlier in the year of the study which, although evaluated as successful, was more limited in scope and much less sustained than those reported for Seattle, Maryland, or in Australia.

In our study, the variables most consistently associated with helmet wearing (that is significantly associated with helmet wearing in at least five of the six subgroups) were: parental encouragement to wear a helmet; closest friend 
wears a helmet; belief that laws that make children wear helmets are good; and sometimes rides off-road.

Some of the associations found are supported by previous published work by a number of authors. ${ }^{27-31}$ Rivara and colleagues found that cyclists when riding off-road were more likely to wear a helmet. ${ }^{31}$ However, the association between riding off-road and helmet use in any environment had not been previously reported. We found that those who indicated that they sometimes ride off-road reported that they had a higher rate of helmet use in any environment. The reason for this association is not clear. The term "off-road" could describe many different environments including parks, gardens, pavements, as well as mountain bike routes. Further research is being discussed to investigate this.

A number of variables, previously found to be associated with helmet use, were not included in the questionnaire given to the students: perceptions of risk, regular use of seat belts in cars, parental education, family income, lack of secure helmet storage facilities, and a previous accident involving a head injury. ${ }^{10} 1117202728$ These questions were not included because they were considered either too intrusive for this type of survey, or would elicit responses of questionable accuracy. This removed the opportunity to investigate possible associations with, and confounding by, these variables.

As with many schools based studies, the schools could not be selected in a random manner. The non-significant "schools" term in the logistic regression analysis and the consistency of the results for East Sussex and for Kent, suggest that the different methods of selection or the types of schools selected for the survey may have made no difference to the prevalence estimates or the associations found. This survey cannot, however, be construed as being population based as we have no way of knowing whether the findings from the schools sampled reflect those for schools not in the sample.

Although DiGuiseppi et al commented that self reported helmet wearing rates were much greater than observed rates, ${ }^{10}$ their comparisons were between rates derived from data collected in different parts of the USA one to three years apart, ${ }^{12} 32$ each of which could account for some of the difference observed. Where self reported and observed wearing rates were studied in the same geographic area during the same time period, ${ }^{17}{ }^{25}$ similarities in rates were found. Self reported always or usually wearing a helmet was found to be very highly correlated with wearing a helmet on the most recent cycle ride. ${ }^{17}$ Additionally, work by Rivara and colleagues found that self reported helmet wearing was accurate for $96 \%$ of subjects sampled from their study. ${ }^{33}$ Consequently, fears that the use of self reported helmet wearing may produce biased findings appear to be unfounded.

The advantage of carrying out the logistic regression analyses for the six age/sex/county subgroups was that the replicability of the results could be investigated and confirmed. Where consistency was observed it gives greater strength to our inference around the observed associations. The disadvantage of this approach is that the individual subgroup analyses would be working at a lower power to detect significant associations than a combined analysis across all subgroups. Inspection of the results of the logistic regression analyses suggest, however, that a combined analysis may not have identified any additional variables significantly associated with cycle helmet wearing.

The differences in helmet wearing rates for the two year groups which were found in our study may be explained in two ways: (1) the drop in rates between ages 11 and 15 reflects the increasing independence of the child and the sense of invulnerability that characterises adolescence; or (2) a cohort effect, where the younger group had more, or more recent, exposure to helmet promotion than the older children. A follow up study is planned for 1998 to explore this issue.

This study found that a smaller percentage of girls reported that they wear a helmet than boys. This difference was most marked at age 15. Surprisingly, a substantial number of studies do not report whether there is any variation in use by sex. Little difference was found in the rates for boys and girls in Toronto ${ }^{20}$ and North East Ontario. ${ }^{23}$ In contrast to our study, greater rates of helmet use were found among girls than boys in Seattle. ${ }^{24}$ The reason for this lack of consistency across studies is unclear.

Similar to Dannenberg and colleagues, ${ }^{17}$ this work dichotomised self reported helmet wearing into: "always wears" compared with "sometimes or never wears" a helmet. The primary justification for this was an interest in promoting head protection for the child cyclist on all cycle journeys. The results of this study, however, also provide evidence to suggest that parental encouragement, for example, not only increases the rate with which a child always wears a helmet, but is also associated with a shift in children from the group reporting no helmet wearing to reporting sometimes wears a helmet. A larger effect, therefore, would be estimated if the always versus never dichotomy was considered.

Vulcan and Lane argue that although improving the design of helmets is important, it should not detract from "getting more helmets on heads". ${ }^{8}$ Reviews of previous work which have evaluated the effectiveness of helmet promotion $^{22} 3435$ indicate that the most successful programmes combine a number of health promotion interventions including targeting parents and children. The results of this survey adds support to this. Successful interventions have included: communitywide coalitions; face to face promotion; publicity campaigns; and actions to make helmets more readily available (for example subsidising the purchase price). These have been found to be enhanced by legislation. ${ }^{22}{ }^{34}$ It is our belief that legislators should not seek to make helmet wearing compulsory in the UK at this time. If they were to do so, it would be contested vigorously. In the unlikely event that compulsory helmet wearing 
were to become law before the rates of helmet wearing are increased through other helmet promotion methods, it is our concern that there would be a real danger of a backlash.

\section{Conclusion}

Previous research has shown that promotion of helmet wearing is likely to be most effective if it is multifaceted. Central to the success of such efforts is making helmets more available and affordable. Our research indicates that parental encouragement appears to have an effect on helmet wearing rates which is separate from and additional to peer influences. When designing a helmet promotion programme, therefore, it would have added impact if both parents and children were the focus. Limited but important change is likely to occur with peer and parental programmes.

We would like to thank the staff and students of the schools that We would like to thank the staff and students of the schools that cooperated with us; Andrew Dannenberg for providing us with a copy of his questionnaire on which ours was based; the staff of the South East Institute of Public Health and the members of who provided helpful comments on earlier drafts of this paper and to acknowledge the financial support given by the then
South Thames Regional Health Authority, and the South South Thames Regional Health Authority, and
Thames Regional Office of the NHS Executive.

1 Preston B. The safety of walking and cycling in different countries. In: Tolley R, ed. The greening of urban transport. London: Belhaven Press, 1994

2 Anonymous. When are cyclists going to wear helmets? [Editorial.] Lancet 1988:i:159-60.

3 Bull JP. Cyclists need helmets. BMF 1988;296:1144.

4 Mills PJ. Pedal cycle accidents: a hospital-based study. Crowthorne: Transport and Road Research Laboratory, 1989. (Research report No 220.)

5 Illingworth C. The argument for helmets. BMf 1992;305: $882-3$

6 Thompson RS, Rivara FP, Thompson DC. A case-control study of the effectiveness of bicycle safety helmets. $N \mathrm{Engl} F$ Med 1989;320:1361-7.

7 Thomas S, Acton C, Nixon J, et al. Effectiveness of bicycle helmets in preventing head injury in children: case-control helmets in preventing head in

8 Vulcan P, Lane J. Bicycle helmets reduce head injuries and Vulcan P, Lane J. Bicycle helmets reduce head
should be worn by all. Inj Prev 1996;2:251-2.

9 Bergman AB, Rivara FP, Richards DD, et al. The Seattle Bergman AB, Rivara FP, Richards DD, et al. The Seattle
children's bicycle helmet campaign. Am $\mathcal{F}$ Dis Child children's bicycle

10 DiGuiseppi CG, Rivara FP, Koepsell TD. Attitudes toward bicycle helmet ownership and use by school-age children. Am $\mathcal{F}$ Dis Child 1990;144:83-6.

11 Nakayama DK, Pasieka KB, Gardner MG. How bicycling related injuries change bicycling practices in children. $A m f$ Dis Child 1990;144:928-9.

12 Weiss BD. Bicycle helmet use by children. Pediatrics 1986;77:677-9.
13 Stevenson T, Lennie J. Empowering school students in developing strategies to increase bicycle helmet wearing. Health Education Research 1992;7:555-66.

14 McDermot FT. Helmets for bicyclists-another first for Victoria. Med $\dot{f}$ Aust 1991;154:156-7.

15 Vulcan AP, Cameron MH, Watson WL. Mandatory bicycle helmet use: experience in Victoria, Australia. World $\mathcal{F}$ Surg 1992;16:389-97.

16 Cameron $\mathrm{MH}$, Vulcan AP, Finch CF, et al. Mandatory bicycle helmet use following a decade of helmet promotion in Victoria, Australia - an evaluation. Accid Anal Prev 1994; 26:325-37.

17 Dannenberg AL, Gielen AC, Beilenson PL, et al. Bicycle helmet laws and educational campaigns: an evaluation of strategies to increase children's helmet use. Am f Public Health 1993;83:667-74.

18 Kleinbaum DG, Kupper LL, Morgenstern H. Epidemiological research. Principles and quantitative methods. London: Lifetime Learning Publications, 1982

19 Zelen $M$. The analysis of several $Z \times Z$ contingency tables. Biometrika 1971;58:129-37.

$20 \mathrm{Hu}$ X, Wesson DE, Parkin PC, et al. Current bicycle helmet ownership, use and related factors among school-aged children in metropolitan Toronto. Can $\mathcal{F}$ Public Health 1994;85:121-4.

21 Sacks JJ, Kresnow M, Houston B, et al. Bicycle helmet use among American children, 1994. Inj Prev 1996;2:258-62.

22 Graitcer PL, Kellerman AL, Christoffel T. A review of educational and legislative strategies to promote bicycle educational and legislative strateg

23 Rowe BH, Thorsteinson K, Bota GW. Bicycle helmet use and compliance: a northeastern Ontario roadside survey. Can $\mathcal{F}$ Public Health 1995;86:57-61.

24 Rivara FP, Rogers LW, Thompson DC, et al. The Seattle children's bicycle helmet campaign: changes in helmet use and head injury admissions. Pediatrics 1994;93:567-9.

25 Cote TR, Sacks JJ, Lambert-Huber DA, et al. Bicycle helmet use among Maryland children: effect of legislation and use among Maryland children. effect

26 Macknin ML, Medendorp SV. Association between bicycle helmet legislation, bicycle safety education, and use of bicycle helmets in children. Arch Pediatr Adolesc Med 1994; 148:255-9.

27 Cohen D. Bicycle accidents. Med f Aust 1986;144:114-5.

28 Gielen AC, Joffe A, Dannenberg AL, et al. Psychosocial factors associated with the use of bicycle helmets among children in counties with and without helmet use laws. $f$ Pediatr 1994;124:204-10.

29 Finch CF. Teenagers' attitudes towards bicycle helmets three years after the introduction of mandatory wearing. Inj Prev 1996;2:126-30.

30 Pendergrast RA, Ashworth CS, DuRant RH, et al. Correlates of children's bicycle helmet use and short-term failure of school-level interventions. Pediatrics 1992;90: 354-8.

31 Rivara FP, Thompson DC, Thompson RS, et al. Injuries involving off-road cycling. F Fam Pract 1997;44:481-5.

32 Wasserman RC, Waller JA, Monty MJ, et al. Bicyclists, helmets and head injuries: a rider-based study of helmet use and effectiveness. Am $\mathcal{F}$ Public Health 1988;78:1220-1.

33 Rivara FP, Thompson DC, Thompson RS. Epidemiology of bicycle injuries and risk factors for serious injury. Inj Prev bicycle injuries

34 Towner E, Dowswell T, Jarvis S. Reducing childhood accidents. The effectiveness of health promotion interventions: a literature review. London: Health Education Authority, 1993

35 Sowden, A Sheldon T, Pehl L, et al. Preventing unintentional injuries in children and young adolescents. Effective Health Care 1996;2(5):1-16. 